Research Article

\title{
Design of Two-Wheeled Motorcycle Tire Crown Contour Bioinspired by Cat Paw Pads
}

\author{
Congzhen Liu, ${ }^{1,2}$ Guolin Wang $\oplus^{1},{ }^{1}$ Haichao Zhou, ${ }^{1}$ Ye Mei $\oplus^{1},{ }^{1}$ Yongqiang $\mathrm{Li}^{2}{ }^{2}$ Yalong Li, ${ }^{2}$ \\ and Lingxin Zhang ${ }^{1}$ \\ ${ }^{1}$ School of Automotive and Traffic Engineering, Jiangsu University, Zhenjiang 212013, China \\ ${ }^{2}$ School of Transportation and Vehicle Engineering, Shandong University of Technology, Zibo 255049, China \\ Correspondence should be addressed to Guolin Wang; glwang@ujs.edu.cn
}

Received 29 July 2020; Revised 13 October 2020; Accepted 23 October 2020; Published 18 November 2020

Academic Editor: Qiguo Rong

Copyright (c) 2020 Congzhen Liu et al. This is an open access article distributed under the Creative Commons Attribution License, which permits unrestricted use, distribution, and reproduction in any medium, provided the original work is properly cited.

\begin{abstract}
The grip force of tires is crucial for vehicle security and drivability under different driving conditions. A small contact area and stress concentration in the contact patch of two-wheeled motorcycle (TWM) tires result in a reduction in grip performance and wear resistance. Even worse, improving the grip and wear resistance together is difficult to achieve. The purpose of the current study is to analyze the dynamic grounding characteristics and geometry of a cat paw pad and then apply its structure to the TWM tire to improve the contact area and wear resistance under different operating conditions. A nonlinear finite element tire model that could accurately reconstruct the tire structure and realistically reflect the mechanical response to different loads was employed. Then, the accuracy of the tire model was validated by a static test with a control tire. For cats, the dynamic grounding characteristics and topology of paw pads were determined using a pressure-sensitive walkway and a three-dimensional (3D) laser scanner. The results indicated that the cat forepaw third pad (CFTP) exhibited excellent grip capacity. According to similarity transformation, a bionic tire crown was designed according to the lateral fitting curve of the CFTP. Comparative results showed the enlargement of the contact area and decreases in peak pressure and frictional energy rate for the bionic tire under different conditions. With these improvements, the grip performance was improved, and the service life was extended synchronously. These research results can be applied for the design of TWM tires, especially cross-country motorcycle tires.
\end{abstract}

\section{Introduction}

As the only components that are in contact with roads, tires play a crucial role in the transmission of groundvehicle forces. The interface between the road and the tire is responsible for many tire performance aspects, such as wear resistance and grip [1]. Generally, there is a conflict between grip and wear resistance performances. That is, improved grip performance means a reduction in wear resistance to some extent and vice versa [2]. Moreover, the interaction at the contact patch is a complex mechanical problem, and the distribution of contact stress is affected by the vehicle's operating conditions, load, road characteristics, tire structure and geometry, and other factors [3]. In severe cases, the deterioration of grip performance may lead to traffic accidents [4].
To assess the critical influence of grip performance on vehicle safety, many studies have focused on the subject, such as sliding contact with roads. For example, Rosen et al. presented a laboratory investigation on the variation of the tire sliding grip coefficient depending on the tire construction, inflation pressure, vertical load, and wheel camber [5]. Taking into account the rubber viscoelasticity, road randomness, pressure, temperature, and speed, Farroni et al. developed a friction model to evaluate the accurate sliding frictional coefficient under various conditions [6]. Boutylin et al. investigated the dependence between the friction coefficient and wheel slip as a function of deformation, adhesion, absolute slip velocity, and road roughness [7]. Since 2012, the EU and Korean governments have instituted a tire labeling system. Thus, wet grip is gaining more attention. Based on fluid-structure 
coupling theory, Chiu and Shui found that tires with outer transverse grooves exhibited an approximately $8 \%$ increase in the wet grip compared with those with only straight grooves [8]. Jeon et al. proposed a new laboratory alignment procedure for wet grip measurement to improve the reproducibility of wet grip testing results [9]. Based on orthogonal experimental design and finite element simulation, the significant factors affecting the wet grip of tires have been identified through several experiments [10]. Other aspects of grip performance were also researched. According to the strain information inside the tire, Carcaterra and Roveri presented a novel brush-rod-beam theoretical model for the identification of the tire-road grip level [11]. Nizard et al. explored an on-line observer that monitored the soil-tire contact longitudinal grip to improve the stability of off-road vehicles [12]. To generate the maximum possible tire grip for a Formula Student single-seat race car, Rao presented a suspension design package [13]. Sabri and Abda developed a tire model and road pavement for footprint and grip coefficient analyses [14]. In the above studies, models, simulations, algorithms, and experiments were adopted to investigate the various influencing factors on grip force. All offered important contributions to grip improvement. However, the effect of the grip optimization methods listed above on wear resistance was not discussed.

A two-wheeled motorcycle (TWM) must lean when steering, which is an important difference from four-wheel vehicles. Moreover, the ground position of the tires changes during steering compared with straight driving. Under this condition, tires must provide sufficient grip force to prevent sliding. However, a mature design method to achieve this objective does not exist [15].

Currently, bionic design is primarily used in vehicle. Functional and structural bionic technologies are used in the design of various vehicle components such as tires. For instance, leopard-like claw tires have been developed by Continental AG to increase the ground area during braking, which reduces the braking distance [16]. The polar bear toe shape has been applied to the tread pattern to improve the grip performance on icy and snowy pavements [17]. A bionic rubber model based on a camel hoof was exploited for desert vehicles [18]. Inspired by the geometric honeycomb structure, Mao et al. determined the mechanism of wear resistance and wet-skid resistance with a complete bionic coupling design method for tire tread compounds [19].

The main objective of this study was to propose an innovative tire crown with reliable grip performance and service life. A cat paw pad with excellent grip properties was chosen as the bionic prototype [20-22]. A pressure-sensitive walkway and a 3D laser scanner were used to determine the dynamic grounding characteristics and topology of cat paw pads. Based on the lateral fitting curve of the cat forepaw third pad (CFTP), a bionic tire crown was designed according to similarity transformation. The contact area, pressure distribution, and frictional energy rate were compared for the control tire and bionic tire. The results showed that the bionic tire had a larger contact area, lower wear rate, and more uniform pressure distribution under different conditions, which successfully improved grip and wear resistance.
With these improvements, the bionic tire could promote the driving, braking, and handling stability of a TWM and prolong tire working life.

\section{Materials and Methods}

2.1. Care and Training of Cats. Five client-owned cats (Chinese Felis silvestris catus) were selected, and owner consent was obtained for each cat. The group consisted of two males, one neutered female, and two neutered males. The mean body weight and age were $2.90 \mathrm{~kg}$ and three years, respectively. All the cats were clinically healthy based on physical examinations performed by veterinarians. Each cat was trained to walk on plywood at its own pace without accelerating, stopping, or turning around. However, almost all the cats expressed curiosity or fear during the process. Food, toys, luminous spots, and affection were used to encourage walking. Before data collection, the cats were housed and cared for in the data-collection room for one week. This study was approved by the institutional ethics committee of Jiangsu University. All cats were fed in accordance with the China Animal Health Regulations.

2.2. Equipment and Data Collection. Ground contact pressure was tested using a pressure-sensitive walkway (Medical Sensor 5101QL Animal Walkway System, Tekscan). The entire walkway surface was covered with a nonslip, thin rubber mat to keep the measuring area out of the cats' sight, prevent slipping, and protect the equipment [23]. To ensure constant speed in each trial, the walkway was embedded into the middle of a $5.00 \mathrm{~m}$ long flush runway. Two transparent polyvinyl chloride (PVC) fences were arranged on both sides to form a straight line for the cats. The Tekscan walkway system was connected to a dedicated computer equipped with software for data collection and storage. The sampling rate was set to $100 \mathrm{~Hz}$ [24]. A high-speed video camera (OLYMPUS i-SPEED) was used to determine the cat's velocity and acceleration for each trial, with its optical axis perpendicular to the cats' walking direction. The sampling rate was $100 \mathrm{fps}$ [25]. Figure 1 shows the test setup. Before data collection, the body weight of each cat was determined using an electronic scale.

As shown in Figure 2, a laser scanner (VIVID 910 3D, Japan) was used to accurately determine the geometric shape of each cat's forepaw pad surface. According to the scanner's specification, the focal distance was set to $600 \mathrm{~mm}$. Each specimen was also located at the focal distance position. Then, the point cloud of the entire pad was obtained, and curve fitting for the lateral point of the CFTP was performed.

2.3. Nonlinear Finite Element Analysis. The fitted lateral curve of the CFTP was scaled up to the same width of a 2.75-18 TWM tire according to similarity transformation theory $[26,27]$. The grip performance of the control tire and bionic tire were simulated and analyzed using nonlinear finite element method. Figure 3(a) shows the finite element model of the 2.75-18 TWM tire. The rubber material of the tire was considered to be well represented by the Yeoh hyperelastic constitutive model, and the cord-rubber composite 


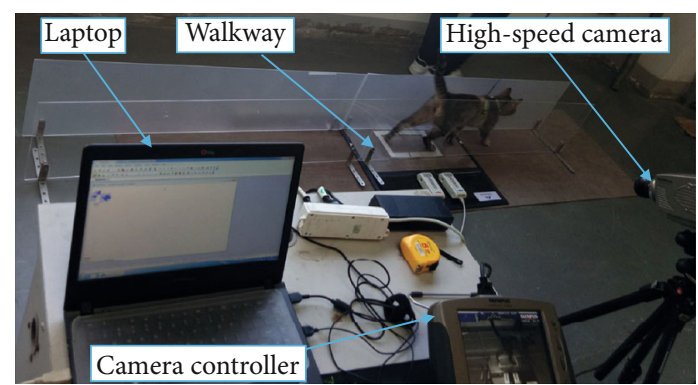

Figure 1: Test setup for force measurement.

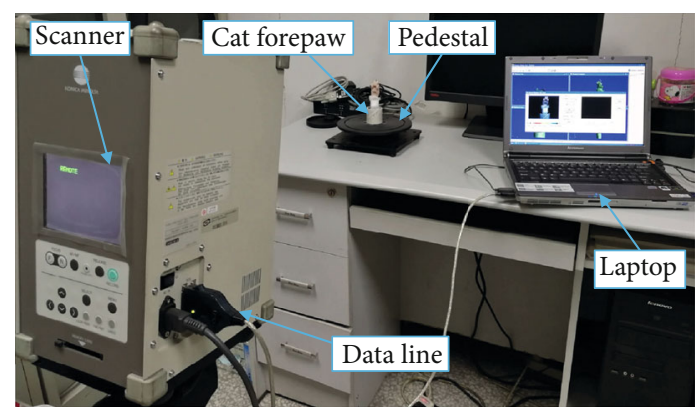

FIGURE 2: Scanning system for the cat forepaw.

material was simulated using the rebar element [28]. The standard inflation pressure and load were $225 \mathrm{kPa}$ and $150 \mathrm{~kg}$, respectively. To simulate different operating conditions, the camber angle was changed, and the frictional coefficient between the tread and the ground was 0.80. In accordance with the simulation operating conditions, the control tire was statically tested to verify the accuracy of the finite element model. Printed paper was placed on the bottom of the platform, and the contact patch shapes were subsequently recorded. Figure 3(b) shows the contact patch extraction for the control tire, where $D$ is the distance from the wheel center to the ground.

The contact areas of the control tire and the bionic tire were analyzed under static, driving, braking, and steering conditions. A concentrated force from the pavement to the tire was imposed for static-state analysis. The driving and braking conditions were simulated by controlling the moving and rotational speed of the tires based on static load analysis. During steering, the tires were simulated by presetting different lean angles.

For the tires, the wear rate can be expressed as a power function of the friction energy generated in the contact patch as follows:

$$
h_{d}=\gamma_{1} E^{\gamma_{2}}
$$

where $h_{d}$ is the radial thickness reduction, $E$ is the frictional energy, and $\gamma_{1}$ and $\gamma_{2}$ are material parameters. The frictional energy density $E_{\tau}^{i}$ at a point $i$ within the tire footprint is defined as follows:

$$
E_{\tau}^{i}=\tau^{i} \mathbf{s}^{i}=\tau_{x}^{i} s_{x}^{i}+\tau_{y}^{i} s_{y}^{i}
$$

where $\tau^{i}$ is the frictional shear force and $\mathbf{s}^{i}$ is the relative slip distance. In the finite element analysis, both the slip distance and the frictional force within the footprint fluctuate with time. The total frictional energy rate $\dot{E}_{\tau}^{i}$ can be computed by time-integrating the nodal frictional energy rate as follows:

$$
\dot{E}_{\tau}^{i}=\sum_{i=1}^{N} \mu F_{V}^{i} \dot{s}^{i}
$$

where $N$ is the total node number within the contact patch, $\mu$ is the coefficient of friction between the tread and the ground, $F_{V}^{i}$ is the nodal contact force, and $\dot{s}^{i}$ is the absolute nodal slip rate [29]. Based on Equation (3), the frictional energy rates of the tire were obtained and compared for the control tire and bionic tire under braking and steering conditions.

\section{Results}

3.1. Data from Pressure-Sensitive Walkway. The vertical forces were normalized to the individual cat's body weight and expressed as \%BW. Meanwhile, each trial velocity was calculated from video captured by a high-speed camera [30]. Figure 4 shows the peak vertical force (PVF) of the entire contact phase at different speeds. The cat forepaw contact process at $0.80 \mathrm{~m} / \mathrm{s}$ is shown in Figure 5, in which the third pad of the forepaw is marked by a red circle.

3.2. Geometry. The pad surface geometry of a cat's forepaw is shown in Figure 6(a), and the surface geometry and point cloud of the third pad were extracted and refined (Figures 6(b) and 6(c)). Fourth-order polynomial fitting was selected for the points at the lateral cross-section (red line in Figure 6(c)), as expressed by Figure 6(d) and Equation (4).

$$
y=0.6564+1.5607 x-1.3955 x^{2}+0.0496 x^{3}-0.0030 x^{4},
$$

where $y$ is the height of the third paw pad, $\mathrm{mm}$, and $x$ is the width of the third paw pad, $\mathrm{mm}$. Based on the fitted lateral curve, a bionic crown was designed for 2.75-18 tires (see Figure 6(e)).

3.3. Model Verification. The test results of the contact area and deflection for the 2.75-18 motorcycle tire control were compared with the nonlinear finite element model. Table 1 shows the $D$ values at different loads. The form of the contact patch is shown in Figure 7 and Table 2. The test results are shown in black and white, and the color photos show the simulated results.

3.4. Comparative Results. The contact area and pressure distribution of the control tire and bionic tire were compared under different conditions. The inflation pressure, load, and frictional coefficient were $200 \mathrm{kPa}, 1.20 \mathrm{kN}$, and 0.80 , respectively. Figure 8 and Table 3 show the results in the static state. 


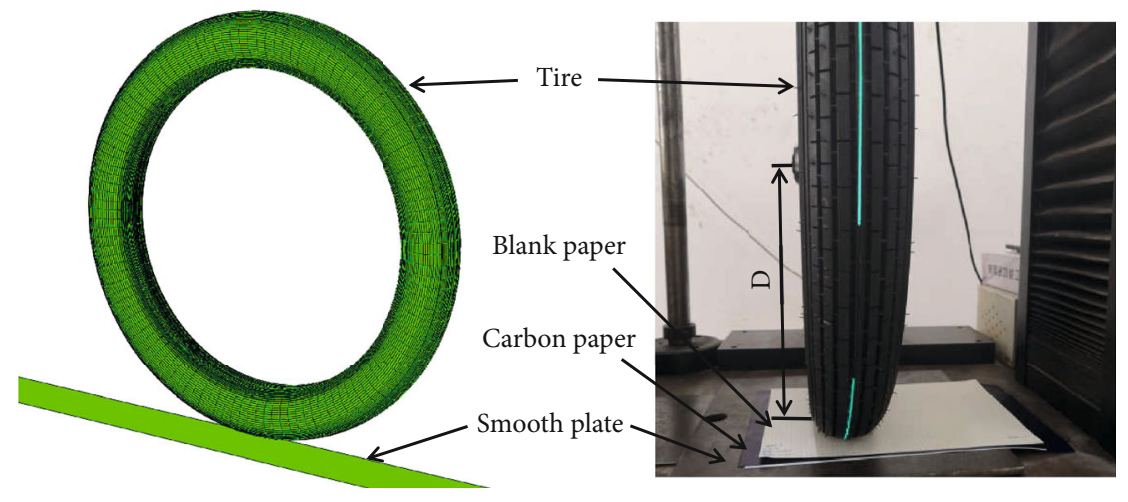

(a)

(b)

Figure 3: 2.75-18 TWM tire: (a) finite element model; (b) test.

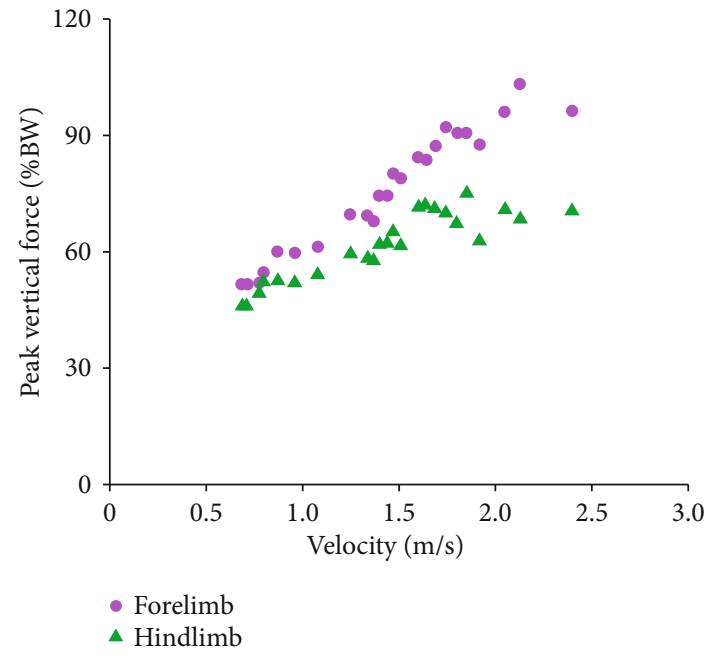

FIGURE 4: Scatter diagram of PVF to velocity.

Owing to the symmetry of tire-road longitudinal forces in driving and braking conditions, only the results under braking conditions were analyzed. The initial velocity and deceleration were set to $16.60 \mathrm{~m} / \mathrm{s}$ and $0.60 \mathrm{~g}$, respectively. Figure 9 and Table 3 show the contact patch, pressure distribution, and frictional energy rate under braking conditions.

During steering, the motorcycle leans at different angles. The velocity was set to $8.30 \mathrm{~m} / \mathrm{s}$, and the roll angles were set to $10^{\circ}, 20^{\circ}$, and $30^{\circ}$ with calculated lateral forces of $104 \mathrm{~N}$, $215 \mathrm{~N}$, and $340 \mathrm{~N}$, respectively. Table 4 and Figures 10-12 show the results for the control tire and bionic tire during steering.

\section{Discussion}

In this study, the ground pressure exerted by five cats moving at different speeds was recorded by encouraging each cat to walk freely across a pressure-sensitive walkway. Data were accepted only if the cats traversed the entire walkway in a straight line without distraction. As shown in Figure 4, the PVF increased with speed, and the PVF of the forepaw was higher than that of the hindpaw, which agreed with previous studies [31-33]. Furthermore, the distinction of PVF between the forepaw and the hindpaw increased with increasing speed. These results suggest that the forepaw plays a leading role in movement. A reasonable interpretation is their different functions: cats are forelimb-dominant in support and steering and hindlimb-driven [24, 34].

The pressure-sensitive walkway adopted in the present test was suitable for the kinetic evaluation of cats. First, there were no constraints on the stride length. Cats could move with different gait patterns, such as walking, trotting, or galloping. Second, compared to the force platform system, the pressure-sensitive walkway could measure the pressure distribution and provide more reliable and detailed data. Third, the force and pressure distributions can be extracted using software, even though several paws contact the equipment simultaneously. Furthermore, the pressure-sensitive walkway was portable and could be installed quickly. Romans et al. used a pressure-sensitive walkway to evaluate the kinetic parameters of cats that have or have not previously undergone onychectomy [35]. This approach has been adopted for cats with osteoarthrosis to evaluate the effectiveness of nonsteroidal anti-inflammatory drug treatment [36]. One disadvantage of this method is that the longitudinal and transverse forces cannot be measured [37].

As shown in Figure 5, the third pad of the forepaw was in early contact with but ultimately deviated from the ground. This phenomenon suggests that the third pad has the longest contact time interval among all pads. Additionally, peak pressure was also achieved at the third pad during the entire walking process. Considering these results, it may be inferred that the third pad of the forepaw appears to play a key role in grip performance. Similar results can be observed at other speeds. Stadig and Bergh analyzed the PVF and distribution of the vertical forces within a paw by dividing the paw print into four equally sized areas: craniolateral, craniomedial, caudolateral, and caudomedial [38]. In these four areas, the caudolateral area supports maximum vertical force, which is different from our result. The first possible reason is that the vertical force of the caudolateral area is the resultant force of all sensors within this area, and the peak pressure distribution was not noted. The second probable reason is the resolution of the equipment. To the authors' knowledge, our study 


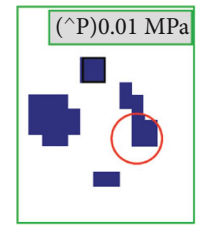

$0.01 \mathrm{~s}$

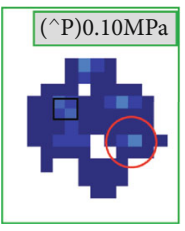

$0.23 \mathrm{~s}$

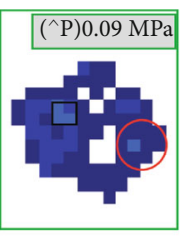

$0.08 \mathrm{~s}$

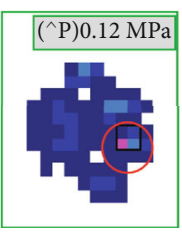

$0.29 \mathrm{~s}$

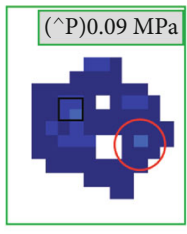

$0.14 \mathrm{~s}$

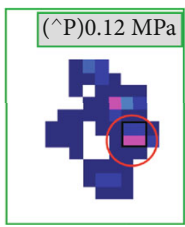

$0.34 \mathrm{~s}$
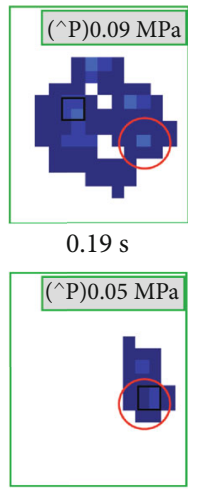

$0.39 \mathrm{~s}$

FIgURE 5: Process of cat forepaw contact at $0.80 \mathrm{~m} / \mathrm{s}$.

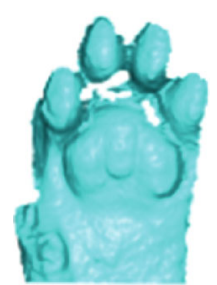

(a)

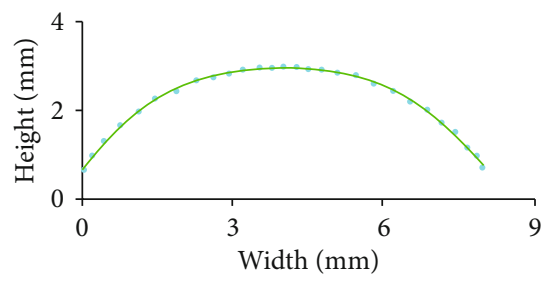

(d)

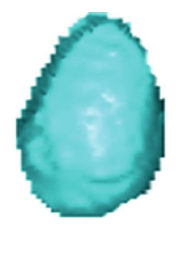

(b)

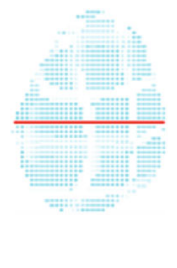

(c)

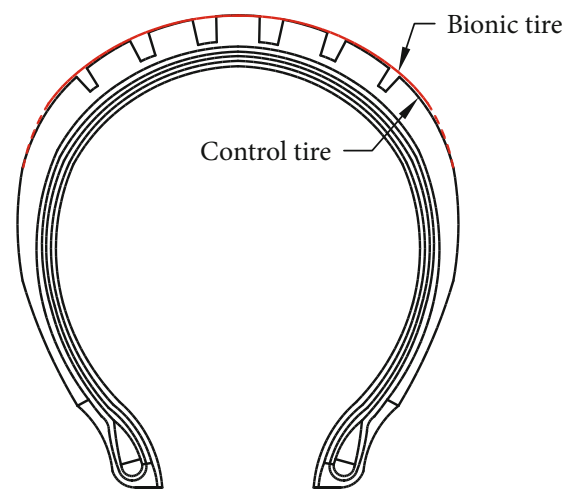

(e)

Figure 6: (a) Geometry of forepaw pad surface; (b) geometry of third forepaw pad; (c) point cloud of third forepaw pad surface; (d) lateral curve fitting of extracted points; (e) type 2.75-18 motorcycle tire.

adopts the densest pressure-sensitive walkway (15.50 sensors per square centimeter) for vertical force measurement of cat pads, which provides more reliable and detailed data.

The accuracy of the finite element model was confirmed by comparing the $D$ value, contact patch shapes, and magnitudes of the control tire and bionic tire. The $D$ value decreased with increasing load. At different loads, each error between the control tire and bionic tire was less than $1.00 \%$ (Table 1). Moreover, the contact patch shapes of the control tire and bionic tire were extremely similar under different loads (Figure 7), and each variation in the contact patch dimensions was less than $4.00 \%$ (Table 2). Comparisons suggested the effectiveness and accuracy of the finite element model. Similar approaches were adopted by previous studies [39, 40].
TABLe 1: $D$ values at different loads.

\begin{tabular}{lccc}
\hline Load $(\mathrm{kN})$ & Control $(\mathrm{mm})$ & Simulation $(\mathrm{mm})$ & Error $(\%)$ \\
\hline 0 & 300.50 & 300.37 & 0.04 \\
0.60 & 294.50 & 292.58 & 0.65 \\
0.90 & 291.50 & 290.08 & 0.49 \\
1.20 & 289.00 & 287.91 & 0.38 \\
\hline
\end{tabular}

The contact area and pressure distribution of tires are important factors for grip performance. Under the same friction coefficient, grip force increases with the contact area enlargement and pressure distribution uniformity [41]. Moreover, contact area enlargement and pressure distribution uniformity are beneficial for the reduction of wear [42]. 


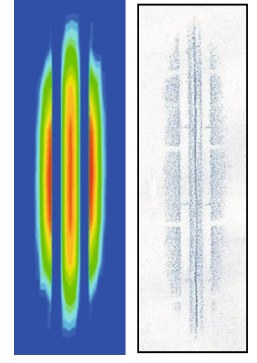

(a)

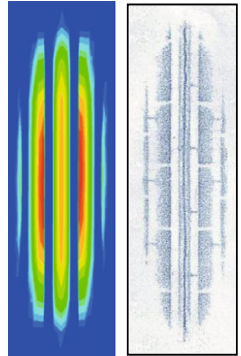

(b)

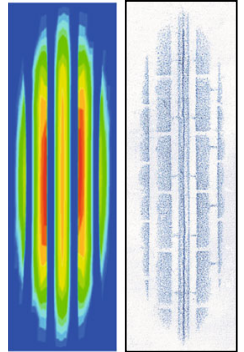

(c)
Figure 7: Comparison of contact patches for 2.75-18 tires at different loads: (a) $0.60 \mathrm{kN}$; (b) $0.90 \mathrm{kN}$; (c) $1.20 \mathrm{kN}$.

TABle 2: Contact patch dimensions for 2.75-18 tires at different loads.

\begin{tabular}{lcccc}
\hline Load $(\mathrm{kN})$ & Items & Control $(\mathrm{mm})$ & Simulation $(\mathrm{mm})$ & Error $(\%)$ \\
\hline \multirow{2}{*}{0.60} & Length & 112.50 & 115.00 & 2.23 \\
& Width & 26.50 & 26.66 & 0.61 \\
\multirow{2}{*}{0.90} & Length & 130.00 & 131.94 & 1.50 \\
& Width & 35.50 & 36.54 & 2.94 \\
\multirow{2}{*}{1.20} & Length & 141.50 & 145.14 & 2.58 \\
& Width & 40.00 & 41.56 & 3.91 \\
\hline
\end{tabular}

In the static state, as shown in Figure 8, it is clear that the contact patch shapes tend to be oval. For the bionic tire, the contact area was $3.10 \%$ larger and the peak pressure was $9.77 \%$ lower than that of the control tire (Table 3). These two improvements indicated the promotion of grip performance.

Under braking conditions, the contact patch shapes resembled a rectangle (Figure 9). For the bionic tire, the contact area expanded by $3.89 \%$, while the peak pressure decreased by $4.10 \%$ in contrast to the control tire (Table 3 ). With these improvements, the bionic tire could achieve greater braking force. Moreover, the frictional energy rate of the bionic tire was $1.23 \%$ less than that of the control tire, which indicated a reduction in wear. Thus, the conflict of grip and wear resistance was alleviated.

Unlike the static and braking conditions, the shapes of the contact patch bent and pressure distribution became asymmetric at steering conditions (Figures 10-12). With the increase of roll angle, the high-pressure region transitioned from the interior to the exterior within the contact patch. At roll angles of $20^{\circ}$ and $30^{\circ}$, it was clear that the deep red color of the bionic tire was wider than that of the control tire. Additionally, the altitude differences between highpressure blocks of bionic tire were lower. Wider highpressure area and lower pressure altitude differences suggested a more uniform pressure distribution. As exhibited in Table 4 , at roll angles of $10^{\circ}, 20^{\circ}$, and $30^{\circ}$, the contact area of the bionic tire increased by $3.00 \%-4.50 \%$, while the peak pressure decreased by $3.50 \%-4.50 \%$ compared with the control tire. Considering the increased contact area and reformation of pressure distribution, it may be inferred that the bionic tire could provide greater lateral force in steering condition, and the stress concentration was also reduced. In addition, within the different roll angles investigated, the frictional energy rate of the bionic tire was $1.44 \%-6.13 \%$ less than that of the control tire. Thus, the bionic tire could improve grip performance and prolong working life simultaneously under steering conditions.

The comparison results above showed that the contact area was enlarged by $3.00 \%-4.50 \%$ under different conditions for the bionic tire. These results could be attributed to the more convex crown on both sides (Figure 6(e)). Most likely, for the enlargement of the contact area, the peak pressure decreased by $3.50 \%-10.00 \%$. In addition, the frictional energy rate decreased by $1.23 \%-6.13 \%$, which could be ascribed to the more uniform pressure distribution and decrease in peak pressure for the bionic tire. With improvements in wear resistance and grip performance, the bionic tire prolonged the working life and improved the handling performance of the TWM synthetically.

Although the inherent conflict between grip and wear resistance performance is intractable, several modifications, such as rubber formula, tread pattern, and tread profile, attempt to alleviate this conflict for four-wheel vehicle tires. Veiga et al. investigated the replacement of carbon black and the number of processing steps to decrease rolling resistance and increase wear resistance and wet grip simultaneously [43]. Because of the obvious impact on braking performance, tread wear, and noise, the stick-slip behavior of the tire tread block was analyzed by a digital image correlation method [44]. Employing an artificial neural network (ANN), Cho et al. presented a crown profile optimization for improving the distribution uniformly of contact pressure, which increased wear resistance and grip performance [45]. In our study, a bionic crown contour was designed for TWM tires. Comparative results show enlargement of the contact area and more uniformity of the pressure distribution. To our knowledge, this is the first study to alleviate this conflict for TWM tires.

A TWM must lean when steering. The lean angle represents the amount of inclination that the vehicle needs to ensure the force balance on a curve. Due to the inherent instability, a TWM remains a particularly dangerous means of transport [46]. Considering an assembly of six rigid bodies with 11 degrees of freedom, Ajmi et al. evaluated the handling performance of a TWM during circulation on a curved track [47]. Formentin et al. addressed a fault taxonomy of a lean angle estimation system to analyze the fault-detection problem and presented a possible solution based on a 4degree-of-freedom inertial sensor [48]. Based on a low-cost sensor configuration, Boniolo et al. proposed an innovative method for estimating the roll angle to evaluate the dynamic properties of a TWM and its tires [49]. These studies considered the vertical force of the tires as a resultant force. Our study analyzed steering conditions with three different roll angles. Moreover, the vertical pressure distribution was considered, which provided more details for grip and wear resistance. To the authors' knowledge, no studies in this context have been conducted for a TWM tire.

In fact, the true reason for producing material loss and wear debris lies in the accumulation of considerable potential energy which is accumulated on the surface of the material 


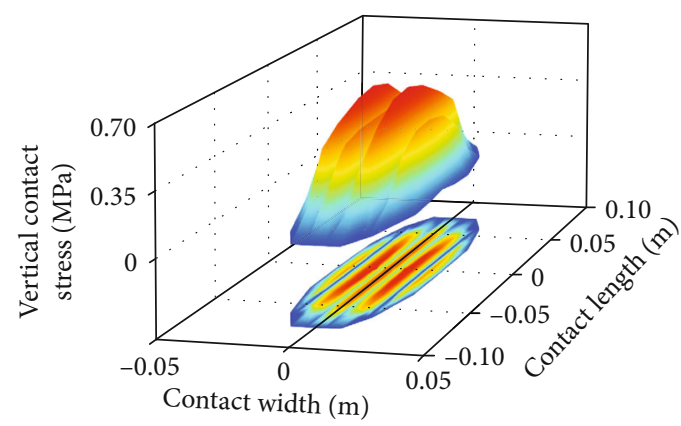

(a)

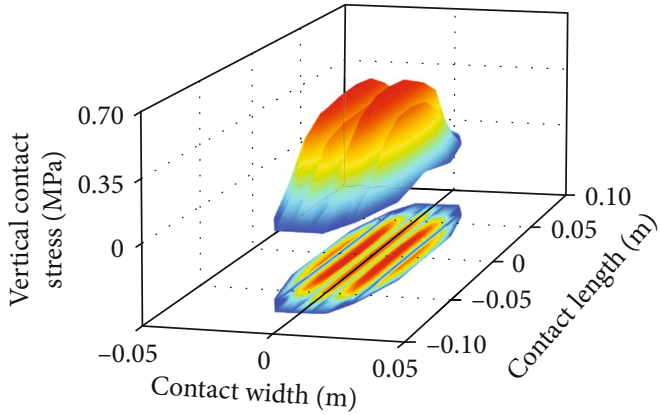

(b)

Figure 8: Contact patch and pressure distribution in the static state: (a) control tire; (b) bionic tire.

TABLE 3: Comparison of the static state and braking condition.

\begin{tabular}{lccccc}
\hline & \multicolumn{2}{c}{ Static state } & \multicolumn{2}{c}{ Braking condition } \\
& Contact area $\left(\mathrm{mm}^{2}\right)$ & Peak pressure $(\mathrm{MPa})$ & Contact area $\left(\mathrm{mm}^{2}\right)$ & Peak pressure $(\mathrm{MPa})$ & Frictional energy rate $(\mathrm{J} / \mathrm{s})$ \\
\hline Control tire & 4313.60 & 0.60 & 5302.60 & 0.44 & 984.43 \\
Bionic tire & 4447.20 & 0.54 & 5513.80 & 0.42 & 972.45 \\
Difference (\%) & 3.10 & 9.77 & 3.89 & 4.10 & 1.23 \\
\hline
\end{tabular}

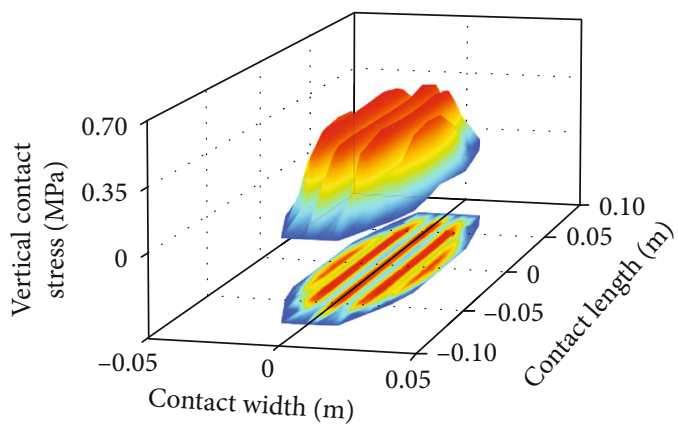

(a)

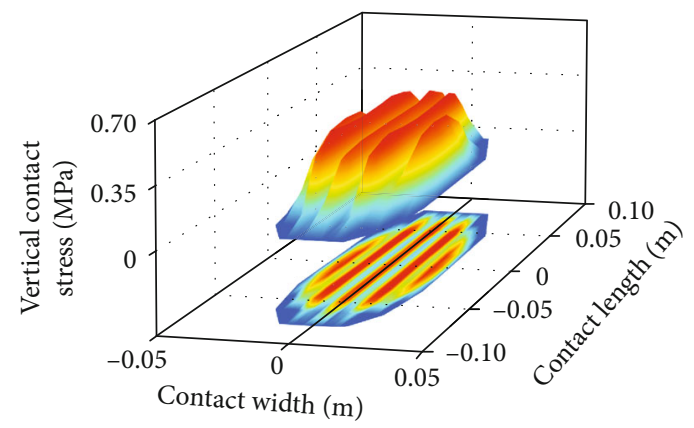

(b)

FIGURE 9: Contact patch and pressure distribution under braking conditions: (a) control tire; (b) bionic tire.

TABle 4: Comparison under steering conditions.

\begin{tabular}{lccccccccc}
\hline & \multicolumn{3}{c}{ Contact area $\left(\mathrm{mm}^{2}\right)$} & \multicolumn{3}{c}{ Peak pressure $(\mathrm{MPa})$} & \multicolumn{3}{c}{ Frictional energy rate $(\mathrm{J} / \mathrm{s})$} \\
\hline Roll angle $\left(^{\circ}\right)$ & 10 & 20 & 30 & 10 & 20 & 30 & 10 & 20 & 30 \\
Control tire & 4115.50 & 4172.10 & 4108.50 & 0.63 & 0.63 & 0.59 & 69.54 & 150.87 & 268.63 \\
Bionic tire & 4298.30 & 4299.20 & 4247.60 & 0.60 & 0.61 & 0.57 & 68.52 & 141.69 & 259.99 \\
Difference (\%) & 4.44 & 3.05 & 3.39 & 4.27 & 3.63 & 3.53 & 1.44 & 6.13 & 3.47 \\
\hline
\end{tabular}

[2]. Therefore, the frictional energy model is widely used for the wear prediction of four-wheel vehicle tires. After analyzing the influence of load, temperature, and speed, Grosch used the energy dissipation and slip speeds to evaluate tire wear [50]. According to a laboratory test for rubber abrasion, Cho et al. adopted a power function wear model for $3 \mathrm{D}$ patterned tires to correlate the wear rate of tread rubber blocks with frictional energy dissipation [29]. Based on an energy dissipation model, Nguyen et al. considered the history dependency of abrasion and directional effects to predict tire tread wear [51]. However, research on this topic for TWM tires is rare. Our research compared the frictional energy rates of control and bionic tires under different conditions and revealed the possible reasons for the wear reduction of bionic tires.

In our previous work, the tire tread and belt structure were reformed with bioinspiration [52]. Meanwhile, the form and area of the contact patch were analyzed in static and braking conditions, which indicated promotion in wear resistance and braking performance. In the present work, the contact area, peak pressure, and frictional energy rate were calculated exactly in static, braking/driving, and steering 


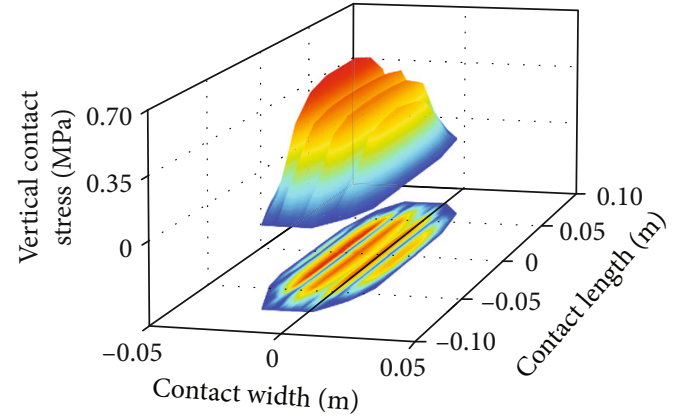

(a)

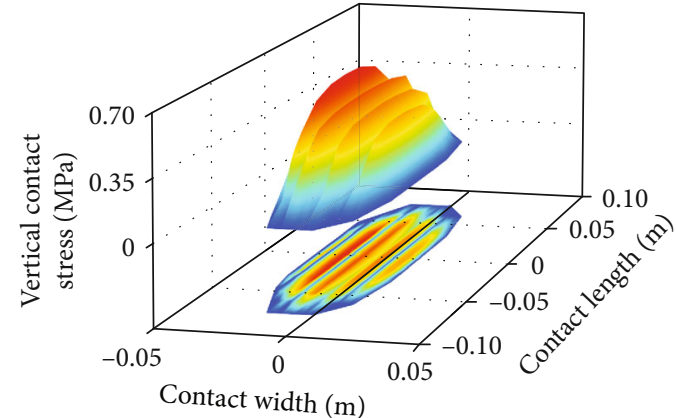

(b)

FIGURE 10: Contact patch and pressure distribution during steering with a $10^{\circ}$ roll angle: (a) control tire; (b) bionic tire.

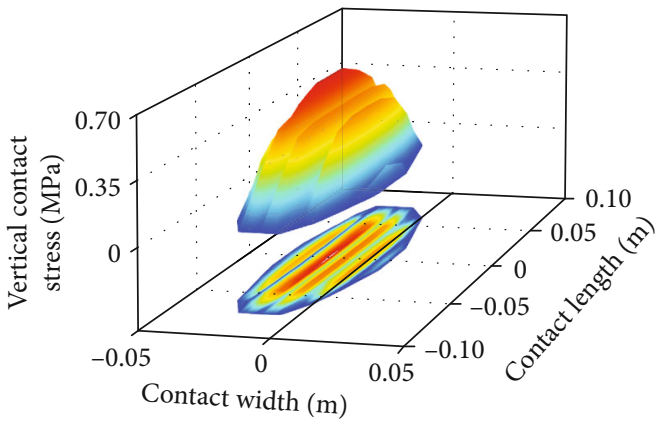

(a)

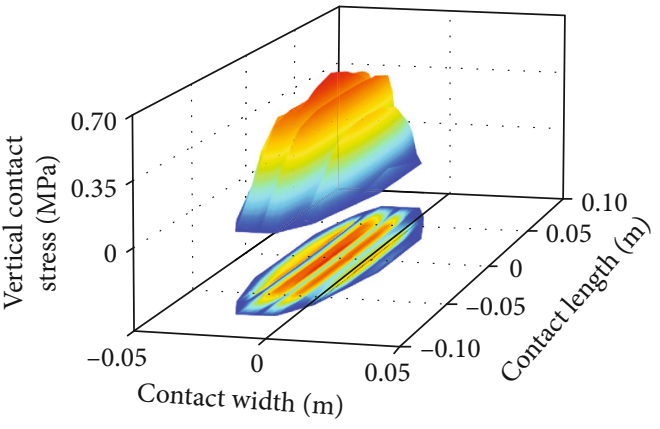

(b)

FIGURE 11: Contact patch and pressure distribution during steering with a $20^{\circ}$ roll angle: (a) control tire; (b) bionic tire.

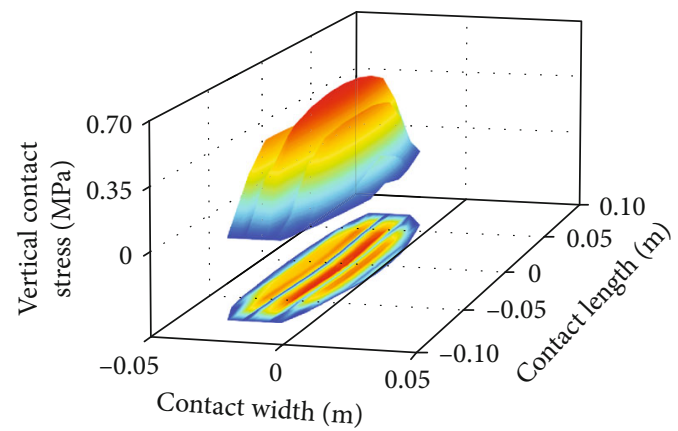

(a)

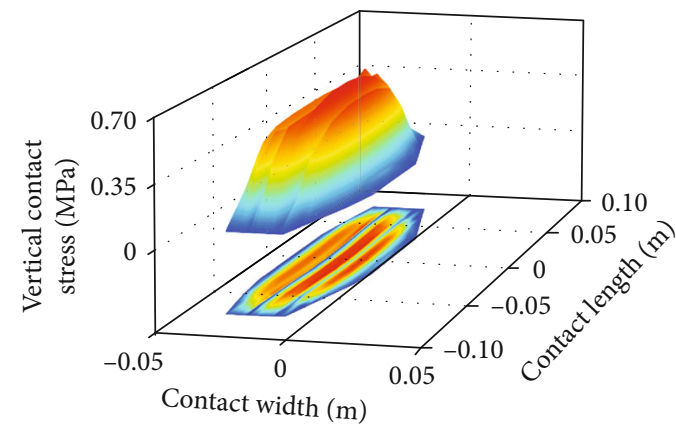

(b)

FIgURE 12: Contact patch and pressure distribution during steering with a $30^{\circ}$ roll angle: (a) control tire; (b) bionic tire.

conditions. Thus, the results were more comprehensive and precise than our previous work.

\section{Conclusions}

In this paper, to improve the grip and wear resistance of a two-wheeled motorcycle tire together, we explore a novel tire crown inspired by a cat paw pad. According to the similarity transformation principle, a tire crown is proposed based on the fitting curve of the CFTP lateral cross-section. Comparative analyses indicate the enlargement of the contact area and decreases in the peak pressure and frictional energy rate for the bionic tire under different operating conditions. These results show that the bionic tire alleviates the inherent conflict between tire wear resistance and grip performance. Thus, this approach can be applied for the design of TWM tires, especially cross-country motorcycle tires. It should be noted that in this study, the proposed tire crown only modifies the tread arc but not the tread pattern, and other tire properties are considered unaltered. To ensure the service life and safety of tires, it will be worthwhile to comprehensively analyze grip, wear resistance, skid wet resistance, and hydroplaning. Additionally, restricted by the capabilities of the pressure-sensitive walkway, only the vertical force and pressure distribution are tested for cat pads. Therefore, a future study will be improved by measuring forces and distributions in three directions simultaneously. 


\section{Data Availability}

The data used to support the findings of this study are available from the corresponding author upon request.

\section{Conflicts of Interest}

None of the authors has any other financial or personal relationships that could inappropriately influence or bias the content of the paper.

\section{Acknowledgments}

The authors would like to thank all the owners who allowed their cats to be used for this research. Additionally, we thank Dr. Yang Wang, Jichao Sun, Yalong Li, and Yang Yuan for taking care of the animals and their resourcefulness in the data collection process. This study is supported by the National Natural Science Foundation of China (grant numbers 51675240 and 51605198), Jiangsu Youth Fund (grant number KB20160528), Jiangsu Province Six Talents Summit Program (grant number JXQC-011), and Jiangsu University Senior Talents Startup Fund Project Funding (grant number 1291120046).

\section{References}

[1] G. Dubois, J. Cesbron, H. P. Yin, and F. Anfosso-Lédée, "Numerical evaluation of tyre/road contact pressures using a multi-asperity approach," International Journal of Mechanical Sciences, vol. 54, no. 1, pp. 84-94, 2012.

[2] A. N. Gentle and J. D. Walter, The pneumatic tire, U. S. Department of Transportation, National Highway Traffic Safety Administration, Washington D C, USA, 2005.

[3] A. G. Veirh, "A review of important factors affecting treadwear," Rubber Chemistry and Technology, vol. 65, no. 3, pp. 601-659, 1992.

[4] B. Chen, X. Zhang, J. Yu, and Y. Wang, "Impact of contact stress distribution on skid resistance of asphalt pavements," Construction and Building Materials, vol. 133, no. 3, pp. 330339, 2017.

[5] I. Rosen, R. Rusi, and I. Plamen, "Laboratory investigation of tyre sliding grip coefficient," Transport, vol. 21, no. 3, pp. 172-181, 2006.

[6] F. Farroni, M. Russo, R. Russo, and F. Timpone, "A physicalanalytical model for a real-time local grip estimation of tyre rubber in sliding contact with road asperities," Proceedings of the Institution of Mechanical Engineers, Part D: Journal of Automobile Engineering, vol. 228, no. 8, pp. 955-969, 2014.

[7] V. Boutylin, J. Lepeshko, and V. Ivanov, "About interrelation between the tire grip properties and the wheel sliding," in 2001 Automotive and Transportation Technology Congress and Exhibition, pp. 372-378, Barcelona, Spain, 2001.

[8] J. T. Chiu and C. R. Shui, "Analysis of the wet grip characteristics of tire tread patterns," Tire Science and Technology, vol. 46, no. 1, pp. 2-15, 2018.

[9] K. Jeon, Y. Yoo, J. Lee, and D. Jung, "Laboratory alignment procedure for improving reproducibility of tyre wet grip measurement," International Journal of Automotive Technology, vol. 17, no. 3, pp. 457-463, 2016.
[10] B. Zhang, M. Zang, T. Zhou, and J. Li, "Optimization on wet grip performance of tires by orthogonal experimental design," China Rubber Industry, vol. 61, no. 3, pp. 143-147, 2014.

[11] A. Carcaterra and N. Roveri, "Tire grip identification based on strain information: theory and simulations," Mechanical Systems and Signal Processing, vol. 41, no. 1-2, pp. 564580, 2013.

[12] A. Nizard, B. Thuilot, and R. Lenain, "Tire longitudinal grip estimation for improved safety of vehicles in off-road conditions," in 2015 IEEE International Conference on Robotics and Automation, pp. 3368-3373, Seattle, USA, 2015.

[13] P. M. Rao, "Development of algorithms for increasing tire grip through frequency response system of the chassis and the spring-damper system," in 8th SAEINDIA International Mobility Conference and Exposition and Commercial Vehicle Engineering Congress, Chennai, India, 2013.

[14] M. Sabri and S. Abda, "Grip analysis of road surface and tire footprint using FEM," in 10th International Conference Numerical Analysis in Engineering, Banda Aceh, Indonesia, 2018.

[15] S. Zhang, G. Cheng, J. Wang, and X. Kang, "Experimental investigation on mode parameters of motorcycle tire," China Rubber Industry, vol. 57, no. 6, pp. 350-353, 2010.

[16] H. Li, "Development status of modern tire technology," Tire Industry, vol. 26, no. 11, pp. 646-651, 2006.

[17] L. Xu, L. Zhou, and J. Cheng, "Development status and prospects of bionic tire research," China Rubber Industry, vol. 65, no. 1, pp. 113-115, 2018.

[18] J. Li, J. Zhuang, and D. Wei, "Design and test of the bionic camel foot rubber tire for desert vehicles," Transactions of the Chinese Society of Agricultural Engineering, vol. 15, no. 2, pp. 32-36, 1999.

[19] C. Mao, Y. Ma, J. Li, and C. Chen, "Study on wet-skid resistance of tire tread compound with bionic coupling," Advances in Intelligent Systems and Computing, vol. 929, pp. 901-908, 2019.

[20] C. Mariti, G. G. Muscolo, J. Peters et al., "Developing biorobotics for veterinary research into cat movements," Journal of Veterinary Behavior, vol. 10, no. 3, pp. 248-254, 2015.

[21] X. Zhang, J. Yang, and H. Yu, "Mechanical buffering characteristics of feline paw pads," Journal of Biomedical Engineering, vol. 29, no. 6, pp. 1098-1104, 2012.

[22] J. Zhang, Z. Zhang, and J. Yang, “On exploring future landinggear system of helicopter based on bionic jumping and damping characteristics," Chinese Quarterly of Mechanics, vol. 31, no. 3, pp. 329-333, 2010.

[23] R. J. Gregor, D. W. Smith, and B. I. Prilutsky, "Mechanics of slope walking in the cat: quantification of muscle load, length change, and ankle extensor EMG patterns," Journal of Neurophysiology, vol. 95, no. 3, pp. 1397-1409, 2006.

[24] E. Schnabl-Feichter, A. Tichy, and B. Bockstahler, "Coefficients of variation of ground reaction force measurement in cats," PLoS One, vol. 12, no. 3, article e0171946, 2017.

[25] B. J. McFadyen, S. Lavoie, and T. Drew, "Kinetic and energetic patterns for hindlimb obstacle avoidance during cat locomotion," Experimental Brain Research, vol. 125, no. 4, pp. 502510, 1999.

[26] F. Wu, J. Xu, and S. Wang, "Qualitative analysis of change in engineering behavior slope in size similarity transformation," Journal of Engineering Geology, vol. 6, no. 2, pp. 128-133, 1998. 
[27] D. Hu and P. Wang, "The theory of similarity and its application in mechanical engineering," Modern Manufacturing Engineering, vol. 32, no. 11, pp. 9-13, 2009.

[28] S. Ying, F. Chen, and G. Wang, "TBR tire modeling and validation based on rebar element," Tire Industry, vol. 27, no. 8, pp. 462-465, 2007.

[29] J. R. Cho, J. H. Choi, and Y. S. Kim, “Abrasive wear amount estimate for 3D patterned tire utilizing frictional dynamic rolling analysis," Tribology International, vol. 44, no. 7-8, pp. 850858, 2011.

[30] K. Voss, T. Wiestner, L. Galeandro, M. Hässig, and P. M. Montavon, "Effect of dog breed and body conformation on vertical ground reaction forces, impulses, and stance times," Veterinary and Comparative Orthopaedics and Traumatology, vol. 24, no. 2, pp. 106-112, 2017.

[31] M. R. Verdugo, S. C. Rahal, F. S. Agostinho, V. M. Govoni, M. J. Mamprim, and F. O. B. Monteiro, "Kinetic and temporospatial parameters in male and female cats walking over a pressure sensing walkway," BMC Veterinary Research, vol. 9, no. 1, p. 129, 2013.

[32] W. C. Renberg, S. A. Johnston, K. Ye, and S. C. Budsberg, "Comparison of stance time and velocity as control variables in force plate analysis of dogs," American Journal of Veterinary Research, vol. 60, no. 7, pp. 814-819, 1999.

[33] E. Schnabl and B. Bockstahler, "Systematic review of ground reaction force measurements in cats," The Veterinary Journal, vol. 206, no. 1, pp. 83-90, 2015.

[34] R. J. Corbee, H. Maas, A. Doornenbal, and H. A. W. Hazewinkel, "Forelimb and hindlimb ground reaction forces of walking cats: assessment and comparison with walking dogs," The Veterinary Journal, vol. 202, no. 1, pp. 116-127, 2014.

[35] C. W. Romans, M. G. Conzemius, C. L. Horstman, W. J. Gordon, and R. B. Evans, "Use of pressure platform gait analysis in cats with and without bilateral onychectomy," American Journal of Veterinary Research, vol. 65, no. 9, pp. 1276-1278, 2004.

[36] M. Guillot, M. Moreau, M. Heit, J. Martel-Pelletier, J. P. Pelletier, and E. Troncy, "Characterization of osteoarthritis in cats and meloxicam efficacy using objective chronic pain evaluation tools," The Veterinary Journal, vol. 196, no. 3, pp. 360367, 2013.

[37] S. C. Budsberg, M. C. Verstraete, and R. W. Soutas-Little, "Force plate analysis of the walking gait in healthy dogs," American Journal of Veterinary Research, vol. 48, no. 6, pp. 915-918, 1987.

[38] S. M. Stadig and A. K. Bergh, "Gait and jump analysis in healthy cats using a pressure mat system," Journal of Feline Medicine and Surgery, vol. 17, no. 6, pp. 523-529, 2015.

[39] H. Zhou, G. Wang, Y. Ding, J. Yang, C. Liang, and J. Fu, “Effect of friction model and tire maneuvering on tire-pavement contact stress," Advances in Materials Science and Engineering, vol. 2015, Article ID 632647, 11 pages, 2015.

[40] G. Wang, J. Ren, J. Yang, C. Liang, and H. Zhou, "Effect study of radial tire contour design to cornering stiffness," Journal of Mechanical Engineering, vol. 51, no. 14, pp. 131-137, 2015.

[41] P. Dolwichai and J. Limtragool, "The effect of tire treads shape to stick-slip phenomenon in frictional contact," in 20th Conference of Mechanical Engineering Network of Thailand, pp. 4185-4188, Nakhon Ratchasima, Thailand, 2006.

[42] Y. Nakajima and F. Takahashi, "Increase of frictional force of rubber block by uniform contact pressure distribution and its application to tire," Rubber Chemistry and Technology, vol. 75, no. 4, pp. 589-604, 2002.

[43] V. D.'. A. Veiga, T. M. Rossignol, J. d. S. Crespo, and L. N. Carli, "Tire tread compounds with reduced rolling resistance and improved wet grip," Journal of Applied Polymer Science, vol. 134, no. 39, article 45334, 2017.

[44] A. J. Tuononen, "Digital image correlation to analyse stick-slip behaviour of tyre tread block," Tribology International, vol. 69, pp. 70-76, 2014.

[45] J. R. Cho, S. W. Shin, and W. S. Yoo, "Crown shape optimization for enhancing tire wear performance by ANN," Computers \& Structures, vol. 83, no. 12-13, pp. 920-933, 2005.

[46] V. Cossalter, R. Lot, and F. Maggio, “A multibody code for motorcycle handling and stability analysis with validation and examples of application," in SAE Technical Paper Series, USA, September 2003.

[47] H. Ajmi, K. Aymen, and R. Lotfi, "Dynamic modeling and handling study of a two-wheeled vehicle on a curved track," Mechanics \& Industry, vol. 18, no. 4, p. 409, 2017.

[48] S. Formentin, I. Boniolo, P. Lisant, C. Spelta, and S. M. Savaresi, "Fault detection in roll angle estimation for two-wheeled vehicles," in 13th IFAC Symposium on Control in Transportation Systems, pp. 54-59, Sofia, Bulgaria, 2012.

[49] I. Boniolo, M. Tanelli, and S. M. Savaresi, "Roll angle estimation in two-wheeled vehicles," IET Control Theory and Applications, vol. 3, no. 1, pp. 20-32, 2009.

[50] K. A. Grosch, "Rubber abrasion and tire wear," Rubber Chemistry and Technology, vol. 81, no. 3, pp. 470-505, 2008.

[51] V. H. Nguyen, D. Zheng, F. Schmerwitz, and P. Wriggers, “An advanced abrasion model for tire wear,” Wear, vol. 396-397, pp. 75-85, 2018.

[52] G. Wang, Y. Ma, C. Liang, and Z. Wan, "Locust's pads bionic structural design of radial tire crown," Journal of Mechanical Engineering, vol. 49, no. 12, pp. 131-135, 2013. 